\title{
Analisis Keandalan Struktur Padeye Berdasarkan Konfigurasi Rigging pada Lifting Upper Deck Modul MODEC dengan Pendekatan Dinamik
}

\author{
Iqbal Gayuh R.M.S, Yeyes M, dan Yoyok S.M \\ Jurusan Teknik Kelautan, Fakultas Teknologi Kelautan, Institut Teknologi Sepuluh Nopember (ITS) \\ Jl. Arief Rahman Hakim, Surabaya 60111 Indonesia \\ e-mail: yeyes@oe.its.ac.id, yoyoksetyo@oe.its.ac.id
}

\begin{abstract}
Abstrak - Dalam perusahaan yang bergerak dalam bidang fabrikasi, lifting merupakan salah satu tahapan terpenting dalam membangun bangunan lepas pantai sehingga diperlukan perhitungan dan analisis tambahan untuk memperhatikan apakah struktur tersebut aman ataupun tidak. Sekenario lifting berdasarkan konfigurasi rigging dapat dibuat untuk menentukan rigging equipment yang tepat. Pada kasus ini, struktur yang di-lifting adalah struktur upper deck dari modul MODEC yang dikerjakan oleh PT. GPS Batam. Deck ini memiliki panjang sekitar $19,5 \mathrm{~m}$ dan lebar $9 \mathrm{~m}$. Berat total struktur dengan equipment sebesar 55 ton. Konfigurasi rigging yang akan digunakan ada tiga, yaitu Model A (tanpa spreader bar), Model B (satu spreader bar), dan Model C (dua spreader bar). Dari ketiga konfigurasi tersebut akan diperoleh dimensi padeye yang berbeda- beda. Model A, Model B, dan Model C memiliki diameter hole padeye masing-masing sebesar $74 \mathrm{~mm}, 65$ $\mathrm{mm}$, dan $52 \mathrm{~mm}$. Tegangan dan UC tertinggi sama- sama terjadi pada Model A sebesar 17625,99 psi dan untuk UC sebesar 0,52. Tetapi hal ini berbanding terbalik apabila ditinjau dari daerah lubang. Tegangan ataupun UC yang lebih tinggi jatuh pada Model C yang menggunakan dua spreader bar sebesar 13936,58 psi dan nilai UC sebesar 0,45. Tegangan yang terjadi di attachments maupun sekitar hole dijadikan variabel dalam mencari keandalan yang terjadi pada tiap padeye dengan metode Mean value first order second moment (MVFOSM). Sehingga didapatkan Probality of Failure (PoF) pada attachments padeye pada Model A, B, dan C masing- masing sebesar 0,126\%, 0,064 $\%$, dan $0,0001 \%$. Sedangkan PoF pada hole padeye sebesar 0,062\% untuk Model A, 0,10\% untuk Model B, dan 0,23\% untuk Model C.
\end{abstract}

Kata Kunci-keandalan, lifting,MVFOSM, padeye, PoF, rigging.

\section{PENDAHULUAN}

$\mathrm{P}$ ROSES pembangunan struktur lepas pantai seperti TLP, submersible, spar, topside module, dan jacket dilakukan di darat oleh perusahan fabrikasi yang berada di daerah waterfront. Fabrikasi/ perakitan tersebut pada umumnya dilakukan terpisah dari site operation bangunan lepas pantai tersebut. Salah satu tahapan perakitan struktur adalah proses lifting [1].

Lifting adalah aktifitas menaikan atau menurunkan sebuah struktur dengan menggunakan crane [2]. Proses lifting terjadi selama fase konstruksi dan instalasi, sehingga sangat penting untuk memahami perhitungan lifting karena perkerjaan tersebut tergantung pada perhitungan lifting [3]. Bisa dikatakan bahwa tahapan lifting adalah salah satu tahap terpenting dalam fabrikasi.

Untuk itu, perhitungan lifting dilakukan dengan sebaik dan seteliti mungkin. Hal-hal yang perlu diantisipasi yang dapat menyebabkan kegagalan struktur saat proses lifting adalah beban struktur sebagai objek lifting maupun beban lingkungan, baik di offshore, onshore, maupun inshore. Beban struktur yang diperhitungkan harus sesuai dengan beban pada kondisi aslinya karena beban tersebut akan terdistribusi melalui lifting point dan menjadi beban sling

Fokus utama dalam penelitian ini adalah melakukan konfigurasi rigging yang akan berdampak pada tegangan di member struktur, dimensi padeye, keandalan padeye dan sling pada lifting upper deck modul MODEC yang dilakukan pada perusahaan PT.Global Process System. Sekenario konfigurasi rigging yang direncanakan adalah empat poin lifting tanpa spreader bar, dengan satu spreader bar, dan dengan dua spreader bar. Setelah melakukan analisis gaya yang terjadi akan menentukan dimensi padeye dan sling properties yang dibutuhkan. Kedua equipment tersebut sangatlah penting selama dilakukan prosed lifting tersebut. Pada konfigurasi rigging maka akan diketahui seberapa besar tegangan yang terjadi pada padeye dan sling. Selanjutnya dilakukan analisis keandalan padeye guna mencari kemungkinan besar terjadinya kegagalan

\section{URAIAN PENELITIAN}

Tahapan dalam analisis lifting hingga mencari keandalan dari struktur padeye dijelaskan sebagai berikut:

\section{A. Pengumpulan Data}

Obyek liftitng yang digunakan adalah struktur upper deck dari modul MODEC. Data yang diperlukan adalah profil material dari struktur upper deck sebagai berikut:

Tabel 1. Data Beam Penyusun Upper Deck

\begin{tabular}{|c|l|c|c|c|}
\hline Item No. & \multicolumn{1}{|c|}{ Deskripsi } & unit $(\mathrm{kg} / \mathrm{m})$ & Length $(\mathrm{m})$ & Weight $(\mathrm{kg})$ \\
\hline 1 & UC $305 \times 305 \times 97$ & 96,9 & 206,71 & 20030,199 \\
\hline 2 & UB356×127×33 & 33,1 & 1,25 & 41,375 \\
\hline 3 & W24×146 & 217,3 & 75,14 & 16327,922 \\
\hline
\end{tabular}

Pada upper deck juga memiliki equipment yang terinstalasi di bagian atasnya dengan berat masing-masing sebagai berikut:

Tabel 2. Equipment Cooler pada Upper Deck

\begin{tabular}{|c|c|c|}
\hline $\begin{array}{c}\text { Item } \\
\text { No. }\end{array}$ & Deskripsi & Weight (kg) \\
\hline 1 & Cooler 1 & 3965 \\
\hline 2 & Cooler 2 & 5138 \\
\hline \multirow[t]{2}{*}{3} & Cooler 3 & 9048 \\
\hline & Total Weight (kg) & 18151 \\
\hline
\end{tabular}




\section{B. Penentuan Centre Of Gravity}

Perhitungan CoG struktur upper deck dihitung secara manual melalui perhitungan material take off (MTO) dari penyusun dan equipment pada upper deck lalu didapatkan letak koordinat titik grafitasinya. .

\section{Beban Angin}

Gaya akibat angin pada proses lifting dapat mempengaruhi kemiringan obyek lifting, sehingga struktur lifting mendapatkan gaya tambah pada sling. Untuk itu perlu dilakukan perhitungan gaya akibat angin dengan menggunakan persamaan berikut [4]:

$$
. F=\frac{1}{2} \rho C A V
$$

Dimana $\mathrm{F}$ adalah gaya angin, $\rho$ adalah massa jenis udara, $\mathrm{A}$ adalah luasan area, dan $\mathrm{V}$ adalah kecepatan angin. Sementara $\mathrm{C}$ adalah koefisien bentuk dari benda yang terkena angin.

Angin yang digunakan untuk perhitungan respons dinamis adalah angin menurut skala beaufort dimana kecepatan angin yang digunakan pada skala 0 hingga 3 .

\section{Pendekatan Respon Dinamis}

Dikarenakan pada saat proses lifting sebuah struktur terikat dan tergantung terkena gaya angin, maka pendekatan untuk mempermudah perhitungan respon dinamis ini adalah dengan melalui pendekatan bandul. Di dalam gerakan bandul/ pendulum terdapat energi kinetik dan energi potensial . Dimana persamaan energi kinetik dan potensial adalah:

$E_{k}=1 / 2 \times \mathrm{m} \mathrm{x} \mathrm{v}^{2}$

$\mathrm{E}_{\mathrm{p}}=\mathrm{m} \times \mathrm{g} \times \mathrm{h}$

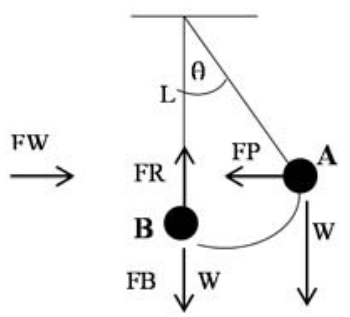

Gambar 1. Gaya-Gaya yang Bekerja pada Bandul

Dari gambar diatas, FW merupakan gaya angin yang dinyatakan pada persamaan (1). Perhitungan ini untuk mendapatkan kecepatan angin yang mengakibatkan penambahan gaya pada struktur yang mendekati dynamic amplitude factor dari DNV sebesar 1,10 untuk onshore. Kecepatan angin yang didapatkan digunakan sebagai beban dinamis pada input permodelan SACS 5.6.

\section{E. Konfigurasi Rigging}

Pada penelitian ini, konfigurasi rigging yang dikenakan pada obyek lifting ada tiga, yaitu Model A (tanpa spreader bar), Model B (dengan satu spreader bar), Model C (dengan dua Spreader Bar).

\section{F. Penentuan Sling}

Untuk menentukan sling properties yang akan digunakan dalam proses lifting diharuskan untuk menghitung kekuatan sling agar tidak terjadi kegagalan. Dalam menentukan sling, nilai yang digunakan adalah minimum breaking load (MBL) melalui persamaan berikut [2]:

Fsling $<\frac{M B L \text { sling }}{\gamma s f}$

Dimana Fsling merupakan gaya sling terbesar dan $\gamma \mathrm{sf}$ merupakan safety factor.

\section{G. Penentuan Shackle}

Shackle merupakan pengait antara sling dari crane dengan padeye. Shackle dalam lifting digunakan untuk menghubungkan sling dengan padeye pada komponen yang diangkat. Nilai beban shackle didapatkan dari beban yang terjadi pada sling. Penentuan shackle menggunakan nilai SWL (Safety Working Load) [2].

Fsling $<S W L \times D A F$

Dimana DAF merupakan Dynamic Amplitude Factor sebesar 1,10 untuk lifting onshore.

\section{H. Desain Padeye}

Padeye adalah sebuah titik lifting yang terbuat dari plat dan diperkuat dengan cheek plate dengan sebuah lubang sebagai tempat yang menghubungkan dengan shackle [3].

Sedangkan penentuan dimensi padeye menurut DNV OSH205 (2014) adalah sebagai berikut:

1. Penentuan diameter luar main plate padeye tidak boleh kurang dari diameter pin hole.

2. Tebal padeye pada area lubang tidak boleh kurang dari $75 \%$ lebar dalam dari shackle

3. Diameter lubang padeye harus secara hati-hati ditentukan agar fit dengan diameter shackle pin. Agar kuat, perbedaan jarak lubang padeye dan diameter pin sekecil mungkin

4. Direkomendasikan untuk diameter shackle pin tidak kurang $94 \%$ dari diameter lubang padeye

\section{Perhitungan Tegangan Padeye}

Tegangan yang terjadi dalam padeye dihitung berdasarkan dua area. Area pertama adalah tegangan pada attachments dan area kedua adalah tegangan pada sekitar lubang.

Pada daerah attachments, padeye yang akan dibuat memiliki stiffner pada depan dan belakang. Attachmentss yang digunakan oleh padeye berbentuk flange. Tegangan- tegangan yang terjadi pada daerah attachments meliputi tensile stress (Ft), shear stress (Fs) dan bending stress (Fba). Sedangkan pada daerah hole, tegangan yang terjadi meliputi tension stress $(\mathrm{Ft})$, shear stress (Fs), tear out stress (Ftr), dan bearing stress (Fbr).

\section{J. Analisis Keandalan}

Keandalan adalah peluang suatu sistem untuk sukses menjalankan tugasnya pada periode waktu tertentu dengan 
lingkungan operasi tertentu pula. Salah satu cara untuk mengukur keandalan adalah dengan cara menggunakan indeks keandalan $\beta$, yang didefinisikan sebagai perbandingan antara nilai rata-rata dan nilai simpang baku keselamatan [5].

Metode yang digunakan dalam analisis keandalan padeye ini adalah Mean value first order second moment (MVFOSM). Metode ini digunakan untuk memperkirakaan keandalan komponen yang tidak dibuat secara massal.

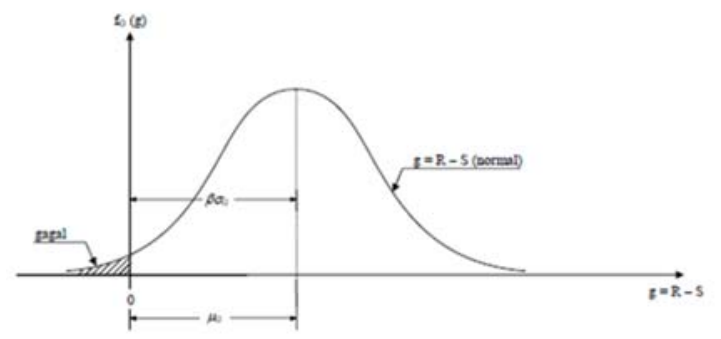

Gambar 2. Grafik Distribus Indeks Keandalan

Pada gambar diatas, $\mathrm{R}$ merupakan kekuatan struktur, sedangkan $\mathrm{S}$ adalah beban yang terjadi pada struktur. Karena $\mathrm{R}$, dan $\mathrm{S}$ adalah normal, maka $\mathrm{g}(\mathrm{R}, \mathrm{S})$ juga normal. $\mu$ merupakan nilai rerata dan $\sigma$ adalah deviasi standar.

Indeks Keandlan $(\beta)$ dapat diperoleh dengan persamaan :

$$
\beta=\frac{\mu_{G}}{\sigma_{G}}=\frac{\mu_{R}-\mu_{S}}{\sqrt{\sigma_{R}^{2}+\sigma_{S}^{2}}}
$$

dan peluang kegagalan (pof) diperoleh dari persamaan :

$$
\begin{aligned}
\mathrm{p}_{t} & =\int_{-\infty}^{0} \mathrm{f}_{\mathrm{G}}(\mathrm{g}) \mathrm{dg} \\
& =\Phi\left(\frac{0-\mu_{G}}{\sigma_{G}}\right)-\Phi\left(\frac{-\infty-\mu_{G}}{\sigma_{G}}\right) \\
& =\Phi\left(\frac{-\mu_{\mathrm{R}}+\mu_{S}}{\sqrt{\sigma_{\mathrm{R}}{ }^{2}+\sigma_{\mathrm{S}}{ }^{2}}}\right)-0 \\
\mathrm{p}_{t} & =1-\Phi(\beta)
\end{aligned}
$$

\section{HASIL DAN DISKUSI}

\section{A. AnalisisMTO, Centre of Grafity dan Distribusi Beban}

Analisis MTO digunakan untuk mendaftar jumlah dan jenis material yang digunakan untuk mendesain suatu struktur. Selain itu, Tujuan dari analisis ini adalah untuk menentukan total berat struktur tersebut. Sehingga dengan diketahuinya jenis dan berat material yang digunakan maka dapat digunakan untuk menentukan titik berat struktur tersebut atau biasa disebut Center of Gravity.

Tabel 1. Koordinat CoG Upper Deck

\begin{tabular}{|c|c|c|c|}
\hline \multirow{2}{*}{ COG Total } & $\mathrm{x}$ & 11285,467 & $\mathrm{~mm}$ \\
\cline { 2 - 4 } & $\mathrm{y}$ & 4146,123 & $\mathrm{~mm}$ \\
\hline
\end{tabular}

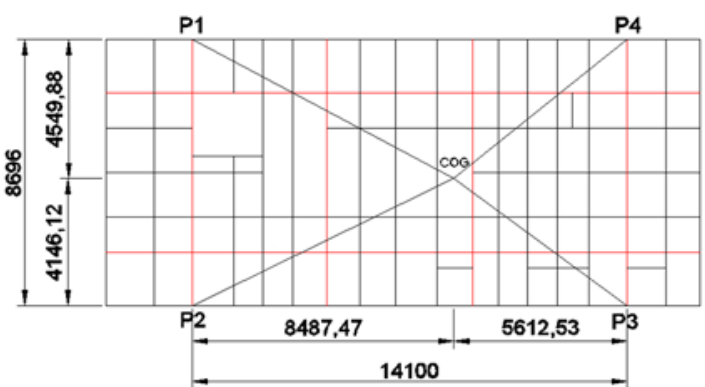

Gambar 1. Letak Posisi CoG Upper Deck

Selanjutnya adalah analisis distribusi beban yang bertujuan untuk menentukan pembagian beban yang bekerja pada masing-masing lifting point selama operasi lifting berlangsung. Lifitng point yang digunakan pada upper deck ini berjumlah empat point lifting yang dimana letaknya ada pada main girder struktur. Beban dengan nilai terbesar akan dijadikan acuan sebagai weight design. Berikut ini merupakan hasil dari perhitungan distribusi beban.

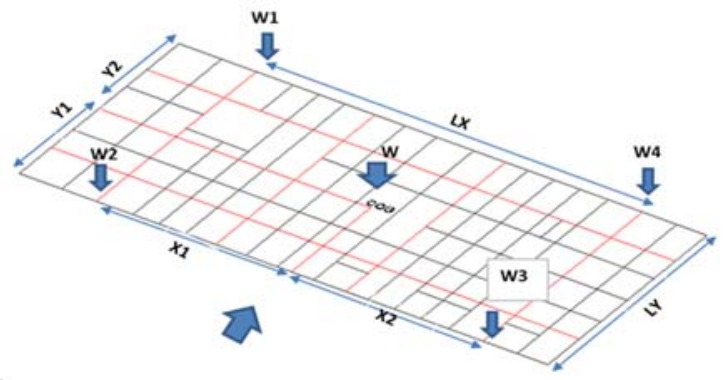

Gambar 2. Distribusi Beban Struktur Lifting

Tabel 2. Nilai Beban pada Masing- Masing Point Lifting
\begin{tabular}{|l|l|}
\hline $\begin{array}{l}\text { Lifting } \\
\text { Point }\end{array}$ & Weight (kg) \\
\hline W1/P1 & 11531.24 \\
\hline W2/P2 & 12654.18 \\
\hline W3/P3 & 19136.11 \\
\hline W4/P4 & 17437.96 \\
\hline
\end{tabular}

Beben terbesar akan digunakan sebagai gaya design dalam menentukan properti dari lifting equipments.

\section{B. Konfigurasi Rigging}

Perhitungan dilakukan berdasarkan tiga konfigurasi lifting yang berbeda, antara lain tanpa menggunakan spreader bar (Model A), dengan menggunakan satu spreader bar (Model B), dan dengan dua spreader bar (Model C). Dimensi yang ditinjau adalah panjang sling, sudut angka sling, panjang dan lebar spreader bar, sedangkan dimensi hook dianggap nol. Dengan menggunakan formula dari Li Liang (2004) [6], maka variasi konfigurasi rigging dapat dimodelkan sebagai berikut: 
1) Model A:

\begin{tabular}{|c|c|c|}
\hline \multicolumn{3}{|c|}{ Dimensi } \\
\hline $\mathrm{Dx}$ & 14100 & $\mathrm{~mm}$ \\
\hline $\mathrm{Dy}$ & 8696 & $\mathrm{~mm}$ \\
\hline $\mathrm{Wh}$ & 0 & $\mathrm{~mm}$ \\
\hline $\mathrm{Xc}$ & 1,437 & $\mathrm{~m}$ \\
\hline $\mathrm{Yc}$ & 0,202 & $\mathrm{~m}$ \\
\hline $\mathrm{Lh}$ & 0 & $\mathrm{~mm}$ \\
\hline $\mathrm{L}_{1}$ & 19277 & $\mathrm{~mm}$ \\
\hline $\mathrm{L}_{2}$ & 19186 & $\mathrm{~mm}$ \\
\hline $\mathrm{L}_{3}$ & 18099 & $\mathrm{~mm}$ \\
\hline $\mathrm{L}_{4}$ & 18196 & $\mathrm{~mm}$ \\
\hline$\theta_{2}$ & 60,05 & $\mathrm{~mm}$ \\
\hline$\theta_{3}$ & 67,32 & $\mathrm{~mm}$ \\
\hline$\theta_{4}$ & 66,08 & $\mathrm{~mm}$ \\
\hline $\mathrm{H}_{4}$ & 16700 & $\mathrm{~mm}$ \\
\hline
\end{tabular}

2) Model B:

Tabel 4. Konfigurasi Rigging Model B

\begin{tabular}{|c|c|c|}
\hline \multicolumn{3}{|c|}{ Dimensi } \\
\hline Dx & 14100 & $\mathrm{~mm}$ \\
\hline $\mathrm{Dy}$ & 8696 & $\mathrm{~mm}$ \\
\hline $\mathrm{Lsp}$ & 6000 & $\mathrm{~mm}$ \\
\hline $\mathrm{L}^{\prime}$ & 17000 & $\mathrm{~mm}$ \\
\hline $\mathrm{Lh}$ & 0 & $\mathrm{~mm}$ \\
\hline $\mathrm{L}^{\prime}$ & 10000 & $\mathrm{~mm}$ \\
\hline $\mathrm{H} 4$ & 15410,4 & $\mathrm{~mm}$ \\
\hline $\mathrm{H} 5$ & 9539,39 & $\mathrm{~mm}$ \\
\hline$\theta$ & 65,0253 & 0 \\
\hline $\mathrm{Y}$ & 72,5424 & 0 \\
\hline
\end{tabular}

3) Model C:

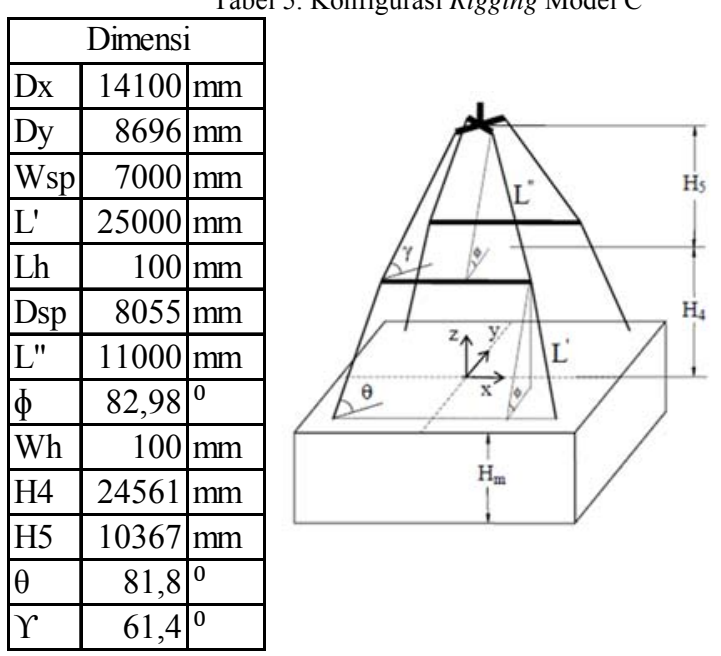

Tabel 5. Konfigurasi Rigging Model C

\section{Perhitungan BebanAngin}

Perhitungan dari respon dinamis ini dilakukan untuk mengetahui seberapa besar gaya dan kecepatan angin yang dapat menghasilkan beban terhadap struktur yang mendekati nilai faktor DAF menurut DNV sebesar 1,1. Dengan menggunakan data angin menurut skala beaufort, didapatkan hasil sebagai berikut:
Tabel 6. Perhitungan Gaya Angin

\begin{tabular}{|c|c|c|c|c|c|c|c|}
\hline Skala & $\begin{array}{c}\text { Kec. } \\
\text { Angin } \\
(\mathrm{km} / \mathrm{jam})\end{array}$ & FW (KN) & $\mathbf{W}(\mathrm{KN})$ & $\boldsymbol{\theta}$ & $\mathrm{Vb}(\mathrm{m} / \mathrm{s})$ & $\begin{array}{c}\text { FR } \\
(\mathbf{K N})\end{array}$ & FR/W \\
\hline 0 & 1 & 0,34 & 541,31 & 0,04 & 0,00 & 541,31 & 1,0 \\
\hline \multirow{4}{*}{1} & 2 & 1,37 & 541,31 & 0,15 & 0,00 & 541,31 & 1,0 \\
\hline & 3 & 3,09 & 541,31 & 0,33 & 0,00 & 541,31 & 1,0 \\
\hline & 4 & 5,49 & 541,31 & 0,58 & 0,01 & 541,31 & 1,0 \\
\hline & 5 & 8,58 & 541,31 & 0,91 & 0,02 & 541,31 & 1,0 \\
\hline \multirow{6}{*}{2} & 6 & 12,36 & 541,31 & 1,31 & 0,04 & 541,32 & 1,0 \\
\hline & 7 & 16,82 & 541,31 & 1,78 & 0,08 & 541,33 & 1,0 \\
\hline & 8 & 21,97 & 541,31 & 2,33 & 0,13 & 541,37 & 1,0 \\
\hline & 9 & 27,80 & 541,31 & 2,94 & 0,22 & 541,47 & 1,0 \\
\hline & 10 & 34,33 & 541,31 & 3,64 & 0,33 & 541,67 & 1,0 \\
\hline & 11 & 41,54 & 541,31 & 4,40 & 0,48 & 542,08 & 1,0 \\
\hline \multirow{8}{*}{3} & 12 & 49,43 & 541,31 & 5,24 & 0,68 & 542,86 & 1,0 \\
\hline & 13 & 58,01 & 541,31 & 6,15 & 0,94 & 544,25 & 1,0 \\
\hline & 14 & 67,28 & 541,31 & 7,14 & 1,27 & 546,64 & 1,0 \\
\hline & 15 & 77,24 & 541,31 & 8,20 & 1,67 & 550,59 & 1,0 \\
\hline & 16 & 87,88 & 541,31 & 9,34 & 2,17 & 556,90 & 1,0 \\
\hline & 17 & 99,21 & 541,31 & 10,56 & 2,77 & 566,73 & 1,0 \\
\hline & 18 & 111,22 & 541,31 & 11,86 & 3,49 & 581,64 & 1,1 \\
\hline & 19 & 123,92 & 541,31 & 13,23 & 4,35 & 603,79 & 1,1 \\
\hline
\end{tabular}

Apabila disesuaikan dengan ketentuan DNV pt2 Ch5Lifting (1996) dimana Dynamic Amplitude Factor untuk lifting di darat sebesar 1,10, maka tepat pada kecepatan angin $18,7 \mathrm{~km} / \mathrm{jam}$ dengan sudut kemiringan 12,8 derajat. Kecepatan tersebut akan digunakan sebagai beban dinamis untuk menentukan unity check dari ketiga konfigurasi pada permodelan SACS

\section{Unity Check Member}

Permodelan dilakukan dengan software SACS 5.6 untuk semua model konfigurasi rigging. Dalam hasil output didapatkan dari ketiga model tersebut menghasilkan UC tertinggi pada member yang sama, yaitu member 0014-0018.

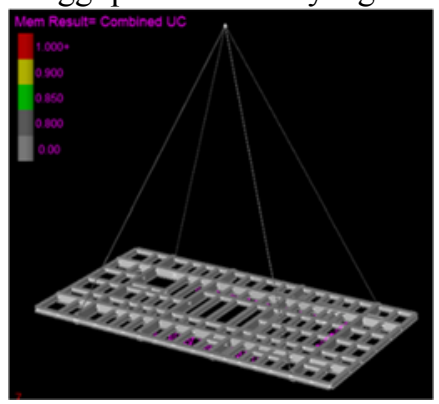

(a)

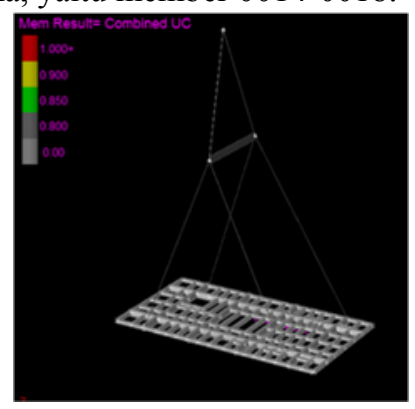

(b)

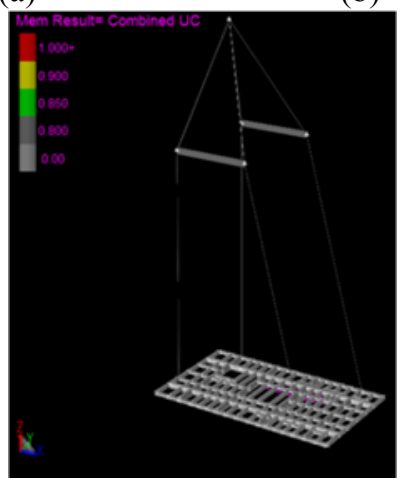

(c)

Gambar 3. Output Unity Check Member pada (a) Model A, (b) Model B, dan (c) Model C. 
Unity check member tertinggi berada pada Model A sebesar 0,281 pada member 0014-0018. Berikut adalah lima member dengan UC tertinggi pada Model A.

\section{E. Penentuan Shackle, Sling, dan Padeye}

Berikut adalah hasil penentuan shackle, sling, dan dimensi padeye pada ketiga model rigging upper deck:

\begin{tabular}{|c|c|c|c|c|c|c|}
\hline \multicolumn{1}{|c|}{ Tabel 8. Shackle Properties } \\
\hline Tipe Model & Tipe & $\begin{array}{c}\text { SWL } \\
(\mathbf{t o n})\end{array}$ & $\begin{array}{c}\text { A } \\
(\mathbf{m m})\end{array}$ & $\begin{array}{c}\text { D1 } \\
(\mathbf{m m})\end{array}$ & $\begin{array}{c}\mathbf{C} \\
(\mathbf{m m})\end{array}$ & $\begin{array}{c}\mathbf{N} \\
(\mathbf{m m})\end{array}$ \\
\hline $\begin{array}{c}\text { Tanpa Spreader bar } \\
\text { (model A) }\end{array}$ & $\underline{\mathrm{A} 085664}$ & 55 & 105 & 70 & 267 & 79,5 \\
\hline $\begin{array}{c}\text { Satu Spreader bar } \\
\text { (model B) }\end{array}$ & $\underline{\mathrm{A} 085556}$ & 42,5 & 95 & 65 & 222 & 57 \\
\hline $\begin{array}{c}\text { Dua Spreader bar } \\
\text { (model C) }\end{array}$ & $\underline{\mathrm{A} 085845}$ & 40 & 74 & 50 & 178 & 45 \\
\hline
\end{tabular}

Tabel 9. Hasil Penentuan Dimensi Padeye

\begin{tabular}{|l|c|c|c|}
\hline \multicolumn{1}{|c|}{ Dimensi } & $\begin{array}{c}\text { Model A } \\
(\mathbf{m m})\end{array}$ & $\begin{array}{c}\text { Model B } \\
(\mathbf{m m})\end{array}$ & $\begin{array}{c}\text { Model C } \\
(\mathbf{m m})\end{array}$ \\
\hline Diameter Hole, Dh & 74 & $\mathbf{6 5}$ & $\mathbf{5 2}$ \\
\hline Radius Main Plate, Rpl & 135 & 130 & 100 \\
\hline Radius Cheek Plate, Rch & 100 & 90 & 70 \\
\hline Tebal Main Plate, Tpl & 50 & 50 & 40 \\
\hline Tebal Cheek Plate, Tch & 20 & 17,5 & 15 \\
\hline Length, L & 410 & 395 & 305 \\
\hline Tinggi, Ht & 335 & 292 & 226 \\
\hline
\end{tabular}

Tabel 9. MBL Sling pada Ketiga Model

\begin{tabular}{|c|c|c|c|}
\hline MBL & Model A & Model B & Model C \\
\hline Sling 1 (kg) & 66291,75 & 63353,5 & 61112,5 \\
\hline Sling 2 (kg) & n/a & 100017 & 108661 \\
\hline
\end{tabular}

\section{F. Perhitungan Tegangan pada Padeye}

Perhitungan tegangan dilakukan berdasarkan dua area pada padeye, yaitu pada attachments dan area sekitar lubang padeye. Berikut adalah hasil dari perhitungan tegangan di area attachments dari ketiga model padeye:

Tabel 10. Hasil Perhitungan Stress pada Area Attachments

\begin{tabular}{|c|c|c|c|c|c|c|}
\hline \multirow{2}{*}{ Nama Model } & \multicolumn{2}{|c|}{ Shear Stress (psi) } & $\begin{array}{c}\text { Tensile } \\
\text { Stress } \\
\text { (psi) }\end{array}$ & $\begin{array}{c}\text { Bending } \\
\text { Stress } \\
\text { (psi) }\end{array}$ & \multicolumn{2}{|c|}{ Total Stress (psi) } \\
\cline { 2 - 7 } & Fsy & Fsx & Ft & Fba & Fy & Uc \\
\hline Model A & 900,6 & 46,9 & 1561,8 & 16091,2 & 17676 & 0,52 \\
\hline Model B & 780,2 & 50,3 & 1675,1 & 10128,5 & 11829,5 & 0,35 \\
\hline Model C & 341,3 & 71,1 & 2369,6 & 4146,5 & 6525,5 & 0,19 \\
\hline
\end{tabular}

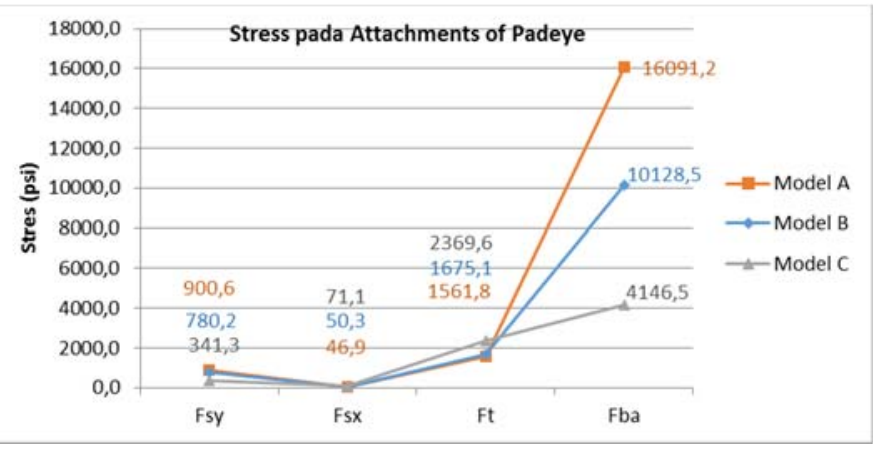

Gambar 4. Grafik Perbandingan Stress pada Area Attachments

Berikut adalah hasil tegangan yang terjadi pada padeye hole:

\begin{tabular}{|c|c|c|c|c|c|c|}
\multicolumn{2}{|c}{ Tabel 11. Hasil Perhitungan Stress pada Area Hole } \\
\hline \multirow{2}{*}{ Nama Model } & Shear Stress (psi) & $\begin{array}{c}\text { Tension Stress } \\
\mathbf{( p s i )}\end{array}$ & $\begin{array}{c}\text { Tear out } \\
\mathbf{( p s i )}\end{array}$ & $\begin{array}{c}\text { Bearing } \\
\text { Stress } \\
(\mathbf{p s i})\end{array}$ \\
\cline { 2 - 7 } & Fsy & Fsx & Ftv & Fth & Ftr & Fbr \\
\hline Model A & 4557,5 & 237,1 & 7903,3 & 3738,7 & 3842,7 & 9051,6 \\
\hline Model B & 4153,6 & 267,5 & 8917,7 & 3721,4 & 3956,3 & 9863,8 \\
\hline Model C & 1986,2 & 413,6 & 13788,1 & 1771 & 5831,2 & 14261,5 \\
\hline
\end{tabular}

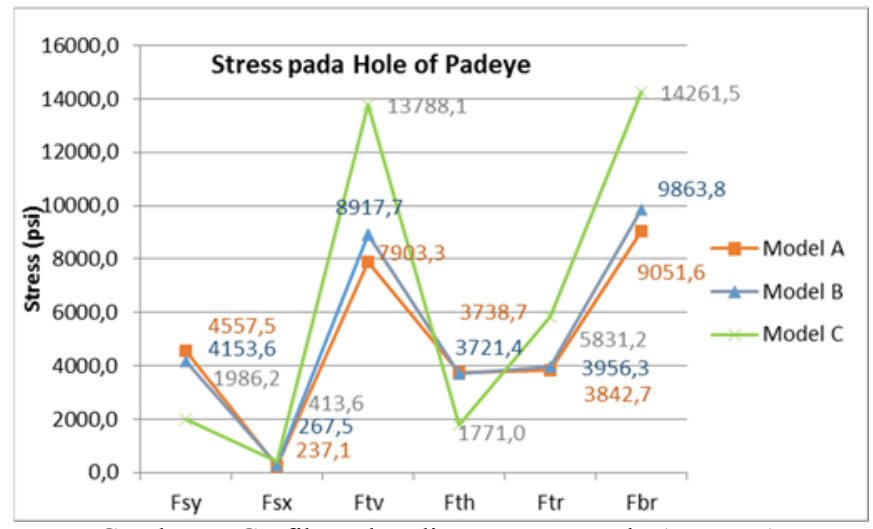

Gambar 5. Grafik Perbandingan Stress pada Area Hole

\section{G. Analisis Keandalan}

Analisis keandalan ditinjau dari dua area kritis yang terdapat pada padeye, yaitu di daerah attachmentss dan hole. Terdapat dua variabel yang digunakan sebagai parameter keandalan metode MVFOSM. Dua variabel tersebut adalah stress/ tegangan yang terjadi pada padeye (S) dan yield strength material padeye (R). Dikarenakan data yang dimiliki hanya berupa tegangan aktual yang terjadi pada padeye, maka diperlukan data- data lain untuk membentuk sebuah distribusi berdasarkan data- data di atas. Untuk itu perlu dilakukan komputasi variabel diatas ke dalam bentuk distribusi normal dengan menggunakan software statitstik.

Berikut adalah nilai keandalan yang didapatkan dari tabel distribusi normal dan nilai dari probability of failure (pof) dari struktur padeye pada masing- masing model. 
Tabel 12. Perhitungan Indeks Keandalan dan Propability of Failure pada Attachmentss dan Hole Padeye

\begin{tabular}{|c|c|c|c|}
\hline \multirow{2}{*}{ Model } & Indeks & Kehandalan & $\begin{array}{c}\text { Probality of } \\
\text { failure }\end{array}$ \\
\cline { 2 - 4 } & $\boldsymbol{\beta}$ & $\mathbf{K}=\boldsymbol{\varphi} \boldsymbol{\beta}$ & $\mathbf{P f}=\mathbf{1}-\boldsymbol{\varphi} \boldsymbol{\beta}$ \\
\hline Tanpa Spread Bar & 3,02 & 0,99874 & $0,126 \%$ \\
\hline Satu Spread Bar & 3,22 & 0,99936 & $0,064 \%$ \\
\hline Dua Spread Bar & 4,91 & 0,999999 & $0,0001 \%$ \\
\hline \multicolumn{4}{|c|}{ Hole } \\
\hline Tanpa Spread Bar & 3,24 & 0,99938 & $0,062 \%$ \\
\hline Satu Spread Bar & 3,08 & 0,99897 & $0,10 \%$ \\
\hline Dua Spread Bar & 2,83 & 0,9977 & $0,23 \%$ \\
\hline
\end{tabular}

\section{KESIMPULAN/RINGKASAN}

Kesimpulan yang didapatkan dari hasil penelitian ini antara lain:

1) Model A memiliki Fsling sebesar 22,09 ton, Model B memiliki Fsling sebesar 21,11 ton, dan Model C memiliki Fsling sebesar 20,37 ton. Pada kecepatan angin 18,7 $\mathrm{km} / \mathrm{jam}$ dan menghasilkan gaya total pada struktur 596,22 $\mathrm{KN}$.

2) Melalui permodelan dengan menggunakan SACS 5.6, hasil member unity check terbesar terdapat pada Model A (tanpa spreader bar) sebesar 0,281 dengan faktor combined load 1,10 pada member. 0014-0018.

3) Pada daerah attachments padeye, tegangan dan UC tertinggi terjadi pada Model A sebesar 17625,99 psi dan untuk UC sebesar 0,52. Pada daerah hole, Tegangan ataupun UC yang lebih tinggi jatuh pada Model C yang menggunakan dua spreader bar sebesar 13936,58 psi dan nilai UC sebesar 0,45 .

4) Pada area attachements padeye, PoF Model A sebesar $0,126 \%$, Model B sebesar 0,064\%, dan Model C sebesar $0,00001 \%$. Sedangkan daerah hole padeye. Model C memiliki nilai PoF yang paling tinggi, sebesar $0,23 \%$, disusul model B sebesar $0,10 \%$, dan Model C sebesar $0,062 \%$.

5) Dari ketiga konfigurasi memiliki keandalan padeye yang cukup tinggi, sehingga ketiga- tiganya aman. Namun dinilai dari ukuran padeye dan lifting equipment yang, Model C memiliki bentuk yang lebih kecil. Sehingga hal tersebut dapat lebih mudah dalam proses instalasinya dan tentunya akan lebih ekonomis.

Lifting pada upper deck dengan menggunakan ketiga konfigurasi memiliki keandalan yang tinggi pada struktur padeye sehingga proses lifting aman digunakan. Namun, melihat dari hasil kesimpulan diatas, Model C lebih direkomendasikan untuk proses lifting upper deck.

\section{UCAPAN TERIMA KASIH}

Penulis I.G.R.M.S ingin mengucapkan terimakasih kepada kedua orang tua, dosen pembimbing, seluruh Staff Pengajar dan Karyawan Jurusan Teknik Kelautan, dan teman- teman penulis yang telah membimbing, membantu, dan mendukung penulis dalam menyelesaikan penelitian ini.

\section{DAFTAR PUSTAKA}

[1] Soegiono. 2004. Teknologi Produksi dan Perawatan Bangunan Laut. Surabaya: Airlangga University Press..

[2] DNV OS H205. 2014. Lifting Operations (VMO Stadard- Part 2-5). Norway: Det Norske Veritas.

[3] El-Reedy, Mohamed A. 2015. Marine Structural Design Calculations.Chennai : MPS Limited

[4] API RP 2A WSD. 2005. Recommended Practice for Planning, Designing and Constructing Fixed Offshore Platforms - Working Stress Design. Washington DC: Amreican Petroleum Institute.

[5] Rosyid, Daniel M. 2007. Pengantar Rekayasa Keandalan. Surabaya : Airlangga University Press

[6] Liang, Li. 2004. Heavy Lift Installaton Study of Offshore Structures. Singapore: National University of Singapore 